\title{
Clinical simulation: innovative educational project in basic cardiopulmonary resuscitation and advanced in pediatrics and neonatology
}

\author{
Pablo García-Molina1, Evelin Balaguer-López', Marta Patiño-Serra1, Alejandro \\ Tortajada-Lohaces ${ }^{1}$, Enrique Sanchis-Sánchez ${ }^{2}, \mathbf{M}^{\mathbf{a}}$ Montserrat Sánchez-Lorente ${ }^{3}$, \\ José María Blasco-Igual ${ }^{2}$ \\ ${ }^{1}$ Department of Nursing, Universidad de Valencia, Spain, ${ }^{2}$ Department of Physiotherapy, \\ Universidad de Valencia, Spain, ${ }^{3}$ Nursing School La Fe, Universidad de Valencia, Spain.
}

\begin{abstract}
Introduction: Nowadays, clinical simulation could be a key link in the teaching and learning of different procedures.

Methodology: It is a quasi-experimental study, using three evaluation questionnaires as a method to collect the respective information to the acquisition of competences and satisfaction of the students regarding a theoretical-practical training on pediatric and neonatal CPR for students of 2nd year Nursing the University of Valencia. To this end, 17 RCP laboratories formed by 228 students were carried out.

Results: The students gave a great reception to this project, giving it a score of 8.82 (SD 0.42) out of 10. The most valued item (by the students) was that in which other students were recommended to do the Pediatric CPR laboratory with a 9.53 out of 10. Student knowledge improved in 7 of the 11 questions and worsened in 4 of them. The one that improved the most was the one referred to the intubation time.

Conclusions: After the simulation, most students said that despite having lived a stressful time they would like to be able to perform more simulations to be able to better fix the theoretical knowledge.
\end{abstract}

Keywords: Cardiopulmonary resuscitation; Pediatrics; Clinical simulation; Educational teaching; Educational innovation. 


\section{Introduction}

The program of Educational Innovation in basic and advanced CPR pediatrics and neonatology is included within the subject "Nursing in Child and Adolescent Health" (ESIA), taught in the 2nd year of the degree in Nursing of the Faculty of Nursing and Podiatry (FIP) of the University of Valencia. It is part of a project of Educational Innovation and Improvement of Teaching Quality of the Servicio de Formación Permanente e Innovación Educativa (SFPIE) of the University of Valencia. This project seeks to experience scenarios where projects are included of innovation of a general nature, aimed at discovering new methodological instruments and new techniques for improving the teaching-learning processes.

In this educational program, taught in the academic year 2017/2018, several clinical situations of the critical pediatric and neonatal context were designed. In these simulations the students of the ESIA subject had to face different scenarios to implement the knowledge, skills and attitudes acquired throughout the academic year. This type of training is based on the new educational paradigm, requires a training of students based on competence. To achieve it, we should incorporate new materials, new methodologies and introduce practices in teaching, thus achieving improvements in the teaching process learning (Calveras, 2003).

The students must be exposed to clinical situations in order to discuss possible solutions. Therefore, the incorporation of clinical simulation in nursing teaching is important, since the professional future will face complex and changing dilemmas to which it must be able to cope (Figueroa, 1999).

Clinical health simulation is defined as a controlled situation of reality. In the case of nursing, it is considered the experience that mimics a realistic environment and that requires individuals or simulators to demonstrate, practice or learn procedures or techniques. Besides, taking decisions and develop a critical thinking in order to provide quality care and insurance for the patient are also of interest (Guimond, Sole, \& Salas, 2011; Urra, Sandoval, \& Irribarren, 2017; Jeffries, 2005).

According to Gaba, considered in some manuals as the "father of simulation", simulation is a teaching technique and not a technology, which should be used to replace or amplify real experiences in guided experiences that replicate substantial aspects of the real world in a interactive way (Casal, 2016; Gaba, 2004).

\section{Project}

Over the years, students of 3rd and 4th have studied other subjects where they have done activities related with CPR in adults but not in children or infants. For this reason, it is 
essential that these students have direct contact with the practices and instruments of the child and neonate dummies to consolidate the knowledge they acquired during previous years.

With the purpose being able to repeat the laboratory it was decided to design this teaching program in collaboration with other subjects (Medical-surgical Nursing, Practicum III, IV and Emergencies and Out-of-Hospital Emergencies), and thus consolidate knowledge and skills within the framework of urgent assistance in the child and serious neonate who needs basic and advanced life support.

The expected results are specified in a special way both in the acquisition of technical training and teamwork with clear objectives. Also of interest are the handling of adequate and specific material, in an environment of difficulty close to reality and in an environmental simulation, with the coordination of the professors of the different subjects and health professionals in active service. These aspects give this program solidity and a high level of experience and perception of the seriousness of the pediatric and neonatal patient before a future action.

The 3rd and 4th year students who participated as monitors in the educational innovation project received prior training, in which they had to respond to the clinical cases raised (cases that were subsequently implemented as monitors). This has allowed them to equip them with the essential qualifications to be able to train the 2nd year students themselves. In addition, it has served to strengthen the knowledge already acquired in their passage through the subject, as they themselves are teaching others classmates.

\section{Aims}

The objectives of the project were:

- $\quad$ All the students of 2nd nursing grade, after the subject of Nursing in Child and Adolescent Health, must know how to correctly perform a CPR in pediatrics.

- Strengthen the population knowledge about pediatric CPR of all 2nd grade students as well as improving the knowledge of 3rd and 4th grade students who participate as monitors.

- Evaluate the knowledge on pediatric CPR before and after the educational intervention, as well as the satisfaction of the students regarding this teaching methodology. 


\section{Metodology}

It is a quasi-experimental study (not controlled) with pretest and post-test, using three evaluation questionnaires as a method to collect the respective information to the acquisition of competences and student satisfaction.

In order to develop the project, 17 CPR laboratories (2 hours duration each) were carried out, in which participated 228 students from the 2nd year of Nursing in Child and Adolescent Health participated.

In practice, seven students from the 3rd and 4th grades of Nursing and 16 nurses participated as monitors of the simulation. Previous and acquired knowledge was evaluated by means of two tests (pre-test and post-test) as wll as the satisfaction of the students with respect to the laboratory by means of a questionnaire passed at the end of the simulation.

The questionnaire to evaluate the satisfaction was anonymous. It was intended to know the opinion about the development of the training, and thus identify elements of improvement.

The questionnaire consisted of 20 items, scored from 0-10 according to the degree of satisfaction or agreement that the students had in this respect, with 0 being the "lowest level of satisfaction or totally disagreeing" and 10 the "grade" highest satisfaction or to be totally in agreement ". Several aspects related to the laboratory were evaluated: laboratory utility, methodology, organization and resources, teaching equipment and general evaluation.

The evaluation of knowledge was carried out with two tests: one before starting the laboratory (pre-test) and the other at the end (post-test). Both questionnaires, like the satisfaction questionnaire, were anonymous, and contained 11 questions. The format was multiple choice questions, only one being correct. For the post-test only the order of the questions was different from the pre-test.

Prior to the laboratories of the subject where the clinical simulations were developed, a theoretical class was given to the students of the 2nd year, where the recommendations of 2015 of the European Resuscitation Council on pediatric and neonatal, basic and pediatric CPR were explained. Subsequently, between April 24 and May 11, 2018, simulation laboratories were carried out. Approximately 15 2nd-year students participated in each laboratory. Three clinical cases were carried out in which the scenario created for this purpose was that of a subway accident where there were multiple victims.

Each case was supervised by a member of the innovation group and the distribution of them was done in the following way:

1. Advanced CPR on pediatric patients 2 years: ESIA teacher.

2. Instrumented CPR in premature RN: student of 3rd or 4th year attached to innovation. 
3. Basic CPR in a 2-month-old infant: 3rd or 4th year student assigned to innovation.

4. Flyer assessment of the tutors: FIP professor assigned to innovation.

The tutor in each case was in charge of evaluating the intervention of the students. The external evaluator was responsible for evaluating through a check-list both the students of 2nd grade and the monitors assigned to the innovation. At the end of the laboratory an analysis of the overall evaluation (debriefing) was carried out.

The distribution of time and functions was carried out in the following way:

Table 1. Distribution of time and functions in the laboratory.

\begin{tabular}{cccc}
\hline & Previous & First part & Second part \\
\hline $\begin{array}{c}\text { Time } \begin{array}{c}\text { Instructors (students and } \\
\text { teachers) } \\
\text { Evaluating teachers }\end{array} \\
\text { Deliver pre-test }\end{array}$ & $\begin{array}{c}\text { Tutorize assigned } \\
\text { clinical case }\end{array}$ & $\begin{array}{c}\text { Collaborate in the } \\
\text { evaluation of students }\end{array}$ \\
ESIA students & Fill check-list & $\begin{array}{c}\text { Lead the evaluation of } \\
\text { the laboratory } \\
\text { (debriefing) }\end{array}$ \\
& Fill pre-test & $\begin{array}{c}\text { Realization of } \\
\text { clinical cases }\end{array}$ & $\begin{array}{c}\text { Active participation. } \\
\text { Fill in post-test and } \\
\text { satisfaction survey }\end{array}$ \\
\end{tabular}

Source: García-Molina, Pablo et al. (2018).

This teaching methodology is important for training of handling an emergency situation because this is very difficult to train and assess during actual emergency. When a critical situation occurs, there is no time to think about what the next step will be. For this reason, it is essential to practice the protocol of action as well as knowing what actions should be performed. The only way to practice an emergency situation (in this case cardiopulmonary resuscitation) without endangering the patient's life is through a simulated environment (De la Horra, 2010).

\section{Results}

The results of the satisfaction survey are shown in graph 1 , where the score for each of the items appears. The average mark awarded by the 228 respondents is 8.82 (SD 0.42) out of 10. The item most valued by the students was 20 (laboratory recommendation) with 9.53 (SD 0, fifty). On the contrary, the worst rated item was question number 6 (teaching methods) with 8.08 (SD 0.52). 


\section{Graph 1: Satisfaction survey results.}

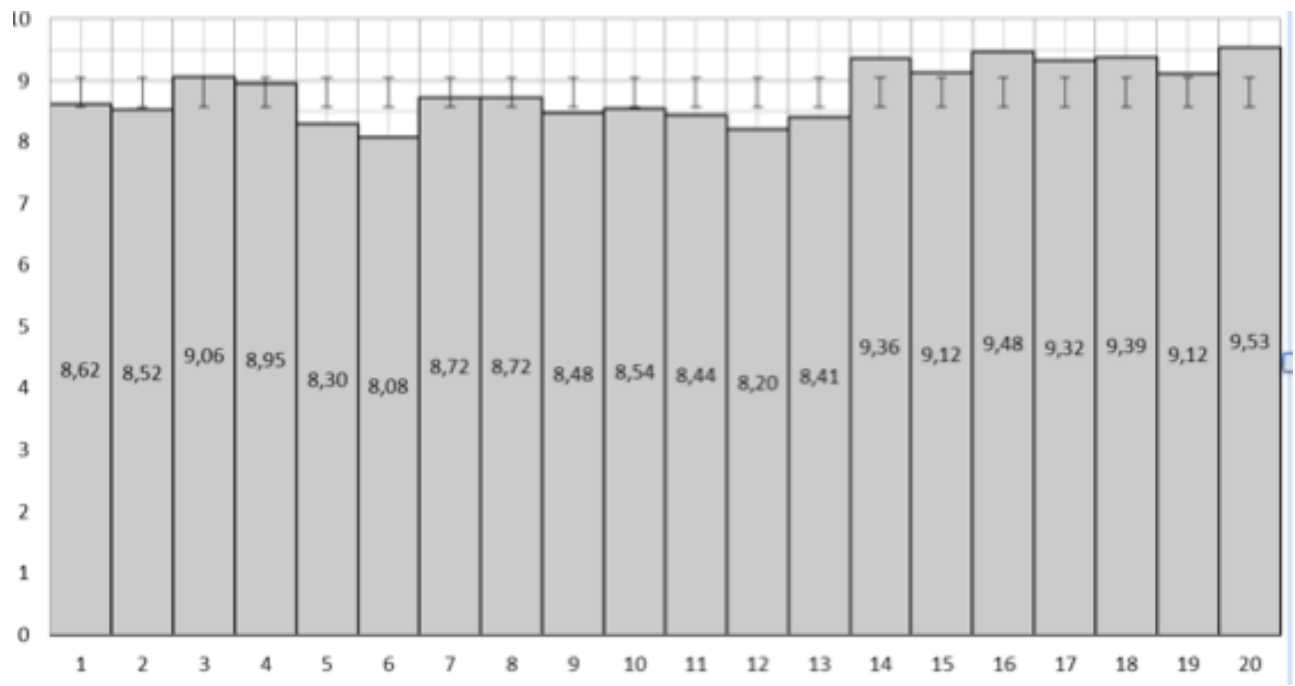

As for the results obtained in the pre-test and post-test, shown in graph 2, the percentage of correct answers and errors in each of the questions is reflected.

\section{Graph 2: Pre-test results vs post-test.}

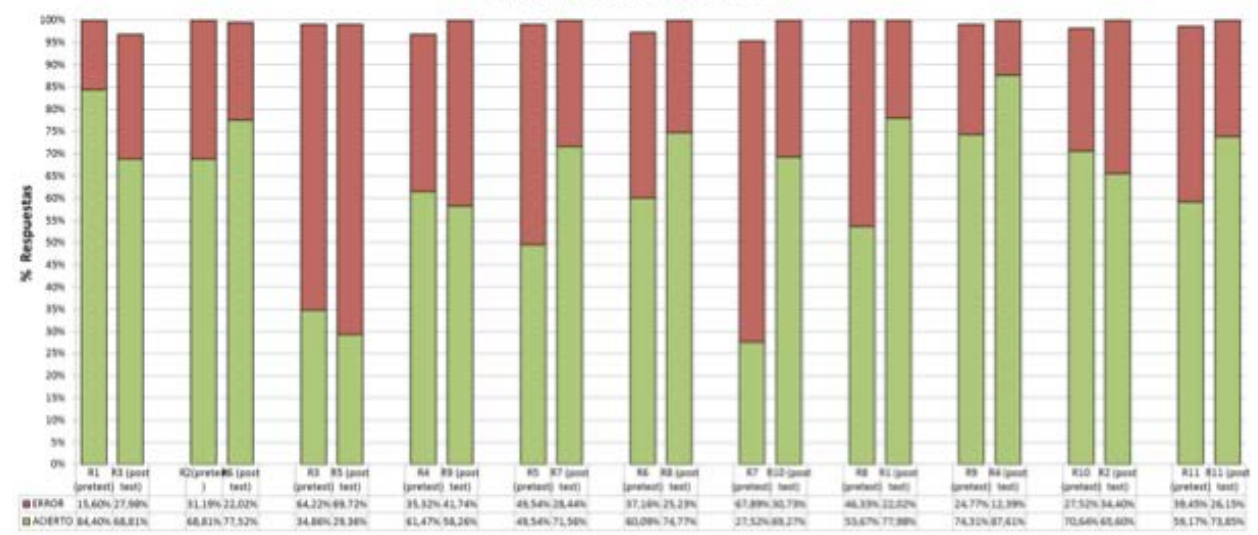

Source: Own elaboration.

The question that received the most success from the pretest was question number 1 (compression-ventilation ratio in children under 2 years). It was guessed by $84.40 \%$ (192) of the students. The question with the fewest guesses in the pretest was 7 (intubation time), correct by $27.52 \%$ (63) of the students. However, this question was the one in which more 
improvement occurred, raising the percentage of correct answers to $77.98 \%$ (178) corresponding to question 11 of the post-test.

Regarding the posttest, the question with the most correct answers was the 9th post-test (material used in an instrumentalized CPR) with a success rate of $87.61 \%$ (200). In this question, the percentage of correct answers was increased by $13.3 \%$ (30) compared to the pre-test. The question with the least successes of the post-test was 5 (chest compression depth of 5 years). This question was answered only by $29.36 \%$ (67).

\section{Conclusions}

The simulations were very well received from students. Although there were stressful situations, many of the students said it was the best way to learn. In addition, it also served to reinforce the knowledge of the students of 3rd and 4th grade of Nursing. For future simulations, the students asked for smaller groups to be made and for more laboratories to be done. Another topic that was also commented was the subject of the material. The students often knew what material had to be used, but not how to use it. In summary, the simulations did not leave any student indifferent and most of them considered that it should be done in other subjects.

\section{References}

Calveras, A. C. (2003). Nuevos planteamientos didácticos: ¿Al innovar en docencia , mejoramos el aprendizaje?, 18-21.

Casal Angulo, M. (2016). La simulación como metodología para el aprendizaje de habilidades no técnicas en Enfermería. Universidad de Valencia.

De la Horra Gutiérrez, I. (2010). La simulación clínica como herramienta de evaluación de competencias en la formación enfermera. Reduca. Universidad Complutense de Madrid.

Durá Ros, M. J. (2013). La simulación clínica como metodología de aprendizaje y adquisición de competencias en Enfermería. Universidad Complutense de Madrid.

Figueroa, A. A. (1999). La innovación en la educación superior en enfermería y los aportes del diseño de instrucción. Revista Latino-Americana de Enfermagem, 7(2), 5-13. http://doi.org/10.1590/S0104-11691999000200002

Gaba, D. (2004). The future vision of simulation in health care. Quality and Safety in Health Care, 13(suppl_1), i2-i10. http://doi.org/10.1136/qshc.2004.009878

García-Molina, Pablo, Blasco, José, Balaguer-López, Evelyn, Tortajada Lohaces, Alejandro, Sanchis-Sánchez, Enrique, Georgieva, Sylvia y Montserrat Sánchez-Lorente, María. (2018). Educational innovation in basic and advanced cardiopulmonary resuscitation in pediatrics and neonatology in a realistic context. 10.4995/HEAD18.2018.7945.

Guimond, M., Sole, M., \& Salas, E. (2011). Getting ready for simulation- based training: A checklist for nurse educators. Nurs Educ Perspect, 32(3), 179-185. 
Jeffries, P. R. (2005). A Framework for Designing, Implementing, and Evaluating Simulations Used as Teaching Strategies in Nursing. Nursing Education Perspectives, 26(2), 96-103.

Urra Medina, E., Sandoval Barrientos, S., \& Irribarren Navarro, F. (2017). El desafío y futuro de la simulación como estrategia de enseñanza en enfermería. Investigación En Educación Médica, 6(22), 119-125. http://doi.org/10.1016/j.riem.2017.01.147

Uv.es. (2017). Convocatoria de proyectos de innovación educativa y mejora de la calidad docente, curso 2017/18. Retrieved January 24, 2018, from https://www.uv.es/

Van Goch, M. (2018). Creativity in liberal education before and after study commencement. 4th International Conference on Higher Education Advances (HEAd'18), 1475-1483. doi: 10.4995/HEAd18.2018.8228.

Van Vugt, M., Hogan, R., \& Kaiser, R. B. (2008). Leadership, followership, and evolution: Some lessons from the past. American Psychologist, 63(3), 182-196. doi: 10.1037/0003066X.63.3.182. 